\title{
1 Thermal acclimation of leaf respiration consistent with optimal plant function
}

2 Han Wang ${ }^{1,2^{*}}$, Owen K. Atkin ${ }^{3,4}$, Trevor F. Keenan ${ }^{5,6}$, Nicholas Smith ${ }^{6,7}$, Ian J.

3 Wright $^{8}$, Keith J. Bloomfield ${ }^{3}$, Jens Kattge ${ }^{9,10}$, Peter B. Reich ${ }^{11,12}$ and I. Colin

4 Prentice ${ }^{1,8,13}$

$5{ }^{1}$ Ministry of Education Key Laboratory for Earth System Modelling, Department of

6 Earth System Science, Tsinghua University, Beijing 100084, China

$7 \quad{ }^{2}$ Joint Centre for Global Change Studies, Beijing 100875, China

$8{ }^{3}$ Division of Plant Sciences, Research School of Biology, The Australian National

9 University, Canberra, ACT 2601, Australia

104 Australian Research Council Centre of Excellence in Plant Energy Biology, 11 Research School of Biology, The Australian National University, Canberra, ACT 12 2601, Australia

$13{ }^{5}$ Department of Environmental Science, Policy and Management, UC Berkeley, 14 Berkeley, CA, USA

$15{ }^{6}$ Climate and Ecosystem Sciences Division, Lawrence Berkeley National Laboratory, 16 Berkeley, CA, USA

$17{ }^{7}$ Department of Biological Sciences, Texas Tech University, Lubbock, TX, USA

$18{ }^{8}$ Department of Biological Sciences, Macquarie University, NSW 2109, Australia

$19{ }^{9}$ Max Planck Institute for Biogeochemistry, Jena, Germany

$20{ }^{10}$ German Center for Integrative Biodiversity Research Halle-Jena-Leipzig, Leipzig, 21 Germany

$22{ }^{11}$ Department of Forest Resources, University of Minnesota, St. Paul, MN 55108, 23 USA

$24{ }^{12}$ Hawkesbury Institute for the Environment, Western Sydney University, Penrith, 25 NSW 2753, Australia

$26{ }^{13}$ AXA Chair of Biosphere and Climate Impacts, Department of Life Sciences, 27 Imperial College London, Silwood Park Campus, Buckhurst Road, Ascot SL5 7PY, 28 UK

29 *Author for correspondence: Han Wang (wanghan_sci@yahoo.com) 


\section{Main}

\section{Introduction}

Terrestrial plant respiration is a major component of the global carbon cycle, releasing ca. $60 \mathrm{Pg} \mathrm{C} \mathrm{yr}^{-1}$ to the atmosphere: six times more than anthropogenic $\mathrm{CO}_{2}$ emissions from all sources combined (Ciais et al. 2014). About half this flux is leaf maintenance respiration in darkness $\left(R_{\mathrm{d}}\right)$ (Atkin et al. 2007). $R_{\mathrm{d}}$ is highly temperature-dependent, following a near-exponential relationship over short time-scales (Heskel et al. 2016). It has been predicted that global warming will increase $R_{\mathrm{d}}$ and accelerate future climate change via a carbon-climate feedback (Cox et al. 2000; Huntingford et al. 2013). However, large uncertainties in future carbon cycle responses to warming persist, likely because model formulations of the temperature responses of photosynthesis and $R_{\mathrm{d}}$ remain poorly constrained by both theory and observations (Ziehn et al. 2011; Booth et al. 2012; Friedlingstein et al. 2014).

Representations of $R_{\mathrm{d}}$ in most land surface models (LSMs) are based on the instantaneous temperature response of $R_{\mathrm{d}}$, governed by enzyme kinetics, relative to a baseline rate, typically at $25^{\circ} \mathrm{C}\left(R_{\mathrm{d}, 25}\right)$ (Atkin et al. 2017). $R_{\mathrm{d}, 25}$ is commonly assumed to be proportional either to area-based leaf nitrogen content $\left(N_{\text {area }}\right)$, or to the maximum rate of carboxylation at $25^{\circ} \mathrm{C}\left(V_{\mathrm{cmax}, 25}\right)$ (Rogers 2014). Predicting photosynthetic traits from $N_{\text {area }}$ is problematic because a large fraction of leaf $\mathrm{N}$ is contained in cell walls (Onoda et al. 2017), and significant fractions are also allocated to other non-photosynthetic functions including defense, storage and osmoregulation (Dong et al., 2017). Many models treat $V_{\mathrm{cmax}, 25}$ and $R_{\mathrm{d}, 25}$ as constant for each plant functional type (PFT), but spatial and temporal trait variations within PFTs are to be expected (Wang et al. 2017b) and have been reported (Kattge et al. 2011, Atkin et al. 2015). Moreover, trait differences observed among PFTs could be caused by acclimation to different environments, rather than intrinsic properties of PFTs.

Experiments have shown acclimation of $R_{\mathrm{d}}$, such that its response to growth temperature over a week or longer is shallower than its response to temperature variation in the short term (Atkin \& Tjoelker 2003; Gifford 2003; Smith \& Dukes 2013; Aspinwall et al. 2016; Drake et al. 2016; Reich et al. 2016; Scafaro et al. 2017). The acclimation of $R_{\mathrm{d}}$ to growth temperature is also evident in spatial observations 
(Atkin et al. 2015; Slot \& Kitajima 2015), showing a far weaker pole-to-equator gradient than would be expected if field-measured $R_{d}$ followed the instantaneous response of $R_{\mathrm{d}}$ to temperature. By analysing the temperature responses of $R_{\mathrm{d}}$ in different datasets, Vanderwel et al. (2015) demonstrated consistency between the observed spatial pattern of $R_{\mathrm{d}}$ and the acclimation of $R_{\mathrm{d}}$ over time. Similar levels of thermal acclimation of photosynthesis and respiration have been shown to occur in different PFTs (Campbell et al. 2007; Smith \& Dukes 2017b). Pervasive $R_{\mathrm{d}}$ acclimation implies a weaker positive carbon-climate feedback than implied by the temperature response of enzyme kinetics (i.e. the instantaneous response) (Reich et al. 2016; Smith et al. 2016; Huntingford et al. 2017). Neglecting acclimation in LSMs is thus a potential major source of bias in Earth system model predictions (Smith \& Dukes, 2013), as recently demonstrated by Huntingford et al. (2017).

Still missing is a theoretical explanation for $R_{\mathrm{d}}$ acclimation. Conclusions from empirical studies alone (Wright et al. 2006) remain subject to the limitations of sampled region, observational period and experimental design. A theoretical basis is essential to build confidence in carbon-cycle predictions (Prentice et al., 2015). As advocated e.g. by Marquet et al. (2014), theories grounded in first principles have the potential to generate explicit quantitative predictions with few assumptions or unconstrained parameters, providing independent standards for comparison with empirical data. Here, we develop such a theory for $R_{\mathrm{d}}$ acclimation, based on the assumption that the various metabolic functions of $R_{\mathrm{d}}$ are coordinated with photosynthetic capacity, indexed by $V_{\text {cmax }}$. In combination with predictions of optimally acclimated $V_{\text {cmax }}$ based on the coordination hypothesis (Chen et al., 1993; Haxeltine \& Prentice, 1996; Maire et al., 2012; Togashi et al., 2018) - whereby optimal $V_{\text {cmax }}$ is just sufficient to use available resources under current average environmental conditions - our approach allows us to formulate and test the sensitivities of the traits of interest $\left(R_{\mathrm{d}}, V_{\mathrm{cmax}}\right)$ to temperature, yielding results applicable to all plants.

Our theory is based on the concept of eco-evolutionary optimality, which derives from the premise that natural selection favours efficient resource allocation by eliminating unsuccessful or uncompetitive trait combinations (Givnish 1986a; Tilman 1999). Optimality-based theories have proven predictive power for plant functions 
including leaf venation networks (Blonder et al. 2017), stomatal behaviour (Cowan 1986; Givnish 1986b; Farquhar et al. 2002; Lin et al. 2015; Wolf et al. 2016; Dewar et al. 2018), leaf-level $\mathrm{CO}_{2}$ drawdown (Prentice et al. 2014), phenology (Kikuzawa et al. 2013; Xu et al. 2017), leaf nitrogen content (Wright et al. 2003; Maire et al. 2012; Dong et al. 2017) and adaptations to elevation (Wang et al. 2017a); and ecosystem processes including vegetation succession (Weng et al. 2017) and primary production (Keenan et al. 2016; Wang et al. 2017b). By linking $R_{\mathrm{d}}$ with optimal $V_{\text {cmax }}$ acclimation (Box 1), we derive quantitative predictions of the thermal sensitivities of acclimated $R_{\mathrm{d}}$ and $V_{\text {cmax }}$ evaluated at the prevailing growth temperature, and at $25^{\circ} \mathrm{C}$. Our theory implies that correlations between $V_{\text {cmax }, 25}$ and $N_{\text {area, }}$ and between $R_{\mathrm{d}, 25}$ and $N_{\text {area }}$ primarily reflect the $\mathrm{N}$ requirements of metabolism (as implied by the coordination hypothesis) rather than 'N limitation' of either $V_{\mathrm{cmax}}$ or $R_{\mathrm{d}}$ - that is, the amount of 'metabolic' $\mathrm{N}$ in the leaf is optimized for current conditions. These predictions are tested using two extensive field observational datasets (Atkin et al., 2015; Smith \& Dukes, 2017).

\section{Materials and Methods}

\section{Theoretical framework}

Leaf dark respiration $\left(R_{\mathrm{d}}\right)$ is closely coupled with photosynthetic activity (Hoefnagel et al. 1998; Wright et al. 2004; Noguchi \& Yoshida 2008; Tcherkez 2012). As described by the standard biochemical model of photosynthesis (Farquhar et al. 1980), the instantaneous rate of photosynthesis by $\mathrm{C}_{3}$ plants is limited either by the capacity of the enzyme Ribulose-1,5-bisphosphate (RuBP) carboxylase/oxygenase (Rubisco) for the carboxylation of RuBP $\left(V_{\mathrm{cmax}}\right)$, or by the rate of electron transport for the regeneration of RuBP, which depends on absorbed light and the electron transport capacity $\left(J_{\max }\right) . R_{\mathrm{d}}$ is used to support diverse metabolic processes including protein turnover, phloem loading, the maintenance of ion gradients between cellular compartments, nitrate reduction, and the turnover of phospholipid membranes. Among these, protein turnover is the largest contributor to $R_{\mathrm{d}}$ variation and is expected to scale closely with $V_{\text {cmax }}$, which sets the daily maximum photosynthetic rate achieved by leaves under natural growing conditions (Amthor 2000; Atkin et al. 2000; Cannell \& Thornley 2000; Bouma 2005). 
138 We start from the assumption that at the prevailing growth temperature, $V_{\text {cmax }}$ is 139 proportional to the overall metabolic activity of the leaf, which is supported by $R_{\mathrm{d}}$. 140 The dimensionless factor $b$ (main text equation (1)) is expected to be constant (for all 141 plants) at a given growth temperature. The value of $b$ at $25^{\circ} \mathrm{C}\left(b_{25}\right)$ has been given as 1420.011 (Farquhar et al., 1980) or 0.015 (Collatz et al. 1991). A constant $b_{25}$ implies that 143 a certain quantity of respiratory enzymes is required for the maintenance of a certain 144 quantity of Rubisco. Our initial attention therefore focuses on the prediction of 145 optimal $V_{\text {cmax }}$ achieved by the acclimation of photosynthetic processes.

146 We hypothesize that $V_{\text {cmax }}$ of leaves at any canopy level acclimates to the current 147 environment so as to be just sufficient to allow exploitation of the average available 148 light. This is the "strong form" (Togashi et al., 2018) of the coordination hypothesis 149 (Chen et al., 1993; Haxeltine \& Prentice, 1996; Maire et al., 2012) (contrasted with 150 the "weak form" that assumes that the total metabolic $\mathrm{N}$ content of the leaf is 151 prescribed, so only the allocation of $\mathrm{N}$ to carboxylation versus electron transport 152 capacities is optimized). The hypothesis leads to a prediction of the 153 ecophysiologically relevant (acclimated) values of both $R_{\mathrm{d}}$ and $V_{\mathrm{cmax}}$ at the prevailing 154 temperature, i.e. the average growth temperature $\left(T_{\mathrm{g}}\right)$. Values of $R_{\mathrm{d}}$ and $V_{\text {cmax }}$ at $25^{\circ} \mathrm{C}$ $155\left(R_{\mathrm{d}, 25}\right.$ and $\left.V_{\mathrm{cmax}, 25}\right)$ are related to quantities of enzymes, while values at growth 156 temperature $\left(R_{\mathrm{d}, \mathrm{tg}}\right.$ and $\left.V_{\text {cmax,tg }}\right)$ are hypothesized to be optimized by the plant. 157 Numerical conversion between values applying to different temperatures is 158 accomplished by applying functions (Kattge \& Knorr, 2007; Heskel et al., 2016) that 159 describe how the instantaneous rates increase with temperature due to enzyme 160 kinetics. To achieve the same level of $V_{\text {cmax }}$, a smaller quantity of Rubisco (and 161 therefore a smaller $V_{\mathrm{cmax}, 25}$ ) is required at a higher temperature (Fig. 1). The 162 coordination hypothesis predicts acclimated values of $R_{\mathrm{d}, \mathrm{tg}}$ and $V_{\text {cmax,tg }}$ that increase 163 with growth temperature, but less steeply than the responses of enzyme kinetics 164 (Togashi et al., 2018). As a result, acclimated values of $R_{\mathrm{d}, 25}$ and $V_{\mathrm{cmax}, 25}$ are predicted 165 to decline with growth temperature. Moreover, because the instantaneous responses of $166 R_{\mathrm{d}}$ and $V_{\text {cmax }}$ to temperature are slightly different, these differences have to be 167 compensated by differences in the acclimated responses of $R_{\mathrm{d}, \mathrm{tg}}$ and $V_{\text {cmax,tg }}$.

168 The reasoning set out above can be represented mathematically, leading to a 169 theoretical derivation of the thermal sensitivities of $R_{\mathrm{d}}, V_{\mathrm{cmax}}$ and their ratio (assessed 
170 at both $T_{\mathrm{g}}$ and $25^{\circ} \mathrm{C}$ ) as follows. We first use the coordination hypothesis to predict 171 the fractional sensitivity of $V_{\text {cmax,tg }}$ to growth temperature (denoted $\beta_{\mathrm{aV}}$, the subscripts $172 a$ and $i$ here represent the acclimated and instantaneous responses, respectively), 173 which is predicted to be less than the instantaneous response, i.e. $\beta_{\mathrm{aV}}<\beta_{\mathrm{iV}}$. The 174 hypothesized proportionality between $R_{\mathrm{d}}$ and $V_{\text {cmax }}$ then links the thermal sensitivity 175 of $R_{\mathrm{d}, \mathrm{tg}}\left(\beta_{\mathrm{aR}}\right)$ with $V_{\text {cmax,tg}}$, since $\beta_{\mathrm{aR}}=\beta_{\mathrm{b}}+\beta_{\mathrm{av}}$. Here $\beta_{\mathrm{b}}$ quantifies the variation of $b$ 176 with temperature, which is due to the slight lower instantaneous thermal responses of $177 R_{\mathrm{d}}\left(\beta_{\mathrm{iR}}\right)$ than $V_{\mathrm{cmax}}$, i.e. $\beta_{b}=\beta_{\mathrm{iR}}-\beta_{\mathrm{iV}}<0$. Making use of the general properties of 178 logarithms, $\beta_{a \mathrm{~V} 25}$ and $\beta_{\mathrm{aR} 25}$ are predicted as a secondary consequence of $V_{\text {cmax,tg }}$ and $179 R_{\mathrm{d}, \mathrm{tg}}$ acclimation combined with enzyme kinetics: $\beta_{\mathrm{aV} 25}=\beta_{\mathrm{aV}}-\beta_{\mathrm{iV}}=\beta_{\mathrm{aR} 25}=\beta_{\mathrm{aR}}-\beta_{\mathrm{iR}}<$ 1800.

\section{Quantitative predictions}

182 Our approach (Box 1) is based on the assumption that acclimated $R_{\mathrm{d}}$ is proportional to 183 photosynthetic capacity, represented by $V_{\mathrm{cmax}}$, where their ratio (b) may be a function 184 of temperature:

$185 \quad R_{\mathrm{d}}=b V_{\text {cmax }}$

186 We therefore first explain quantitative predictions of the thermal acclimation of 187 optimal $V_{\text {cmax }}$.

188 The coordination hypothesis predicts a spatial and temporal pattern in $V_{\text {cmax }}$ assessed 189 at growth temperature, reflecting acclimation to the prevailing environmental 190 conditions of an individual leaf. In response to environmental variations, it predicts 191 that $V_{\text {cmax }}$ can vary vertically within the canopy, geographically among sites, and 192 temporally with atmospheric $\mathrm{CO}_{2}$ concentration and climate (Haxeltine \& Prentice 193 1996; Ainsworth \& Long 2005; Maire et al. 2012). $V_{\text {cmax }}$ values have been shown 194 experimentally to acclimate to sustained changes in growth temperature, such that $195 V_{\text {cmax }}$ assessed at growth temperature (hereafter $V_{\text {cmax,tg }}$ ) increases with growth 196 temperature, while $V_{\mathrm{cmax}, 25}$ declines, along with the Rubisco amount and the fraction 197 of leaf $\mathrm{N}$ allocated to Rubisco (Scafaro et al. 2017).

198 Quantitative predictions of $V_{\text {cmax }}$ can be obtained from the co-ordination hypothesis 199 by equating the Rubisco-limited $\left(A_{\mathrm{C}}\right)$ and electron transport-limited $\left(A_{\mathrm{J}}\right)$ rates of $\mathrm{C}_{3}$ 
200 photosynthesis in the Farquhar et al. (1980) model (Wang et al., 2017b). For 201 simplicity, we shall assume that the light response of $A_{\mathrm{J}}$ under natural light conditions 202 is effectively linear up to the point at which $A_{\mathrm{C}}$ becomes limiting, implying that 203 limitation of photosynthesis by $J_{\max }$ under average field conditions is generally 204 avoided (Wang et al. 2014; Keenan et al. 2016; Dong et al. 2017; Wang et al. 2017a; 205 Togashi et al. 2018). Thus, under field conditions the coordination hypothesis predicts 206 (Dong et al., 2017; Togashi et al., 2018):

$207 V_{\mathrm{cmax}, \mathrm{tg}} \approx \varphi_{0} I_{\mathrm{abs}}\left(\chi c_{\mathrm{a}}+K\right) /\left(\chi c_{\mathrm{a}}+2 \Gamma^{*}\right)$

208 where $\varphi_{0}$ is the intrinsic quantum efficiency of photosynthesis, which is independent 209 of temperature over the normal range of metabolic activity (Collatz et al. 1990), and $210 I_{\mathrm{abs}}$ is the leaf absorbed photosynthetic photon flux density (PPFD). $\chi$ is the ratio of 211 leaf-internal to ambient partial pressure of $\mathrm{CO}_{2}, c_{a}$ is the ambient partial pressure of $212 \mathrm{CO}_{2}, \Gamma^{*}$ is the photorespiratory compensation point, and $K$ is the effective Michaelis213 Menten coefficient of Rubisco. $\Gamma^{*}$ and $K$ are temperature-dependent following 214 Arrhenius relationships measured e.g. by Bernacchi et al. (2001). The least-cost 215 hypothesis (Prentice et al., 2014; Wang et al., 2017b) predicts optimal $\chi$ as a function 216 of growing-season mean values of temperature $\left(T_{\mathrm{g}}\right)$ and vapour pressure deficit $(D)$, 217 and elevation (z). This prediction is quantitatively supported by worldwide 218 measurements of $\chi$ across species and environments (Wang et al. 2017b). Equation (2) 219 yields estimates of $V_{\text {cmax }}$ given $\chi$ and field-relevant average values of $c_{\mathrm{a}}$, temperature 220 and PPFD. The theoretical temperature dependence of $V_{\text {cmax,tg }}$ arises from the separate 221 temperature responses of $\chi, \Gamma^{*}$ and $K$. The sensitivity of $V_{\text {cmax,tg }}$ to temperature can be 222 obtained by differentiating equation (2). Evaluating the result under standard 223 conditions $\left(T_{\mathrm{g}}=25^{\circ} \mathrm{C}, D=1 \mathrm{kPa}, z=0, c_{\mathrm{a}}=40 \mathrm{~Pa}\right)$ yields $\beta_{\mathrm{aV}}=5.5 \% \mathrm{~K}^{-1}\left(\beta_{\mathrm{a} V}\right.$ is the 224 fractional sensitivity of $V_{\text {cmax,tg }}$ to temperature after acclimation: see Box 1 for 225 definitions, Figure 1 for a graphical explanation, and Appendix 1 for derivations). 226 This value derives primarily from the sensitivities of $K$ and $\Gamma^{*}$ to temperature $(8.5 \%$ $227 \mathrm{~K}^{-1}$ and $5.4 \% \mathrm{~K}^{-1}$, respectively), which depend on their activation energies (Bernacchi 228 et al. 2001), and to a lesser extent on the sensitivity of $\chi$ to temperature $\left(0.9 \% \mathrm{~K}^{-1}\right)$.

$229 V_{\text {cmax,tg }}$ is then corrected from $T_{\mathrm{g}}$ to $25^{\circ} \mathrm{C}$ using the enzyme-kinetic temperature 230 response of $V_{c \max }$ (Kattge \& Knorr 2007). Evaluated at $20^{\circ} \mathrm{C}$ (mean $T_{\mathrm{g}}$ in our dataset), 231 this function yields an instantaneous thermal sensitivity of $V_{\mathrm{cmax}}$ of $\beta_{\mathrm{iV}}=9.9 \% \mathrm{~K}^{-1}$, 
232 higher than the acclimated thermal sensitivity $\left(\beta_{\mathrm{av}}=5.5 \% \mathrm{~K}^{-1}\right)$. The thermal 233 sensitivity of acclimated $V_{\text {cmax }, 25}$ is predicted as the difference between the thermal 234 sensitivities of $V_{\text {cmax }}$ acclimated to the growth temperature $\left(V_{\text {cmax,tg }}\right)$ and the 235 instantaneous enzyme-kinetic response of $V_{\mathrm{cmax}}\left(\mathrm{Box} 1: \beta_{\mathrm{aV} 25}=\beta_{\mathrm{aV}}-\beta_{\mathrm{iV}}=-4.4 \% \mathrm{~K}^{-}\right.$ $236^{1}$ ).

237 Heskel et al. (2016) provided an estimate of $R_{\mathrm{d}}$ at a reference temperature $\left(T_{\text {ref }}\right)$ :

$238 \ln R_{\mathrm{d}, \mathrm{ref}}=a+0.1012 T_{\mathrm{ref}}-0.0005 T_{\mathrm{ref}}^{2}$

239 where $a$ is an empirical constant varying among biomes, representing the natural log 240 of the value of $R_{\mathrm{d}}$ at $0^{\circ} \mathrm{C}$. The enzyme-kinetic response of $R_{\mathrm{d}}$ to temperature $\left(\beta_{\mathrm{iR}}\right)$ as 241 given by Heskel et al. (2016) is $8.1 \% \mathrm{~K}^{-1}$ at the mean $T_{\mathrm{g}}$ of the data. The enzyme242 kinetic thermal response of $R_{\mathrm{d}}$ is slightly smaller than $\beta_{\mathrm{iv}}$, and leads to a thermal 243 response of parameter $b$ in equation (1) given by the difference between $\beta_{\mathrm{iR}}$ and $\beta_{\mathrm{iV}}$ $244 \quad\left(\beta_{b}=\beta_{\mathrm{iR}}-\beta_{\mathrm{iV}}=-1.8 \% \mathrm{~K}^{-1}\right)$. This then generates a prediction of $\beta_{a R}=3.7 \% \mathrm{~K}^{-1}$ and $245 \beta_{a \mathrm{R} 25}=-4.4 \%$, which is the same as $\beta_{a \mathrm{~V} 25}$, consistent with the assumption that $b_{25}$ is a 246 constant (Box 1). Derivations are provided in Supporting Information (Appendix 1).

\section{Empirical analyses}

\section{Photosynthesis and respiration data}

249 We combined two $R_{\mathrm{d}}$ datasets. GlobResp (Atkin et al. 2015) contains measurements 250 of $R_{\mathrm{d}}, V_{\text {cmax }}, N_{\text {area }}$ and leaf mass per area (LMA) from 899 species at 100 locations 251 across the major biomes and continents, including data from an earlier compilation by

252 Wright et al. (2004). LCE (Smith \& Dukes 2017a) contains field measurements of 253 leaf carbon exchange (including $R_{\mathrm{d}}$ and $V_{c \max }$ ) and leaf chemical traits (including $N_{\text {area }}$ 254 and LMA) from 98 species at 12 locations spanning $53^{\circ}$ latitude in North and Central 255 America (Fig. S1). $R_{\mathrm{d}}$ measurements in both datasets followed the same protocol. 256 Both were taken on fully expanded leaves in daytime after a period of dark 257 adjustment. Inhibition of respiration in the light was not assessed. $V_{\text {cmax }}$ values in 258 GlobResp were estimated by the 'one-point method' whereas those in LCE were 259 estimated from full $A-c_{\mathrm{i}}$ curves; these methods give closely similar results (De Kauwe 260 et al. 2016). Replicated measurements in LCE on the same species and site were 261 averaged. Juvenile samples were excluded. We index $T_{\mathrm{g}}$ by the mean temperature 
262 during the thermal growing season when temperatures are above $0^{\circ} \mathrm{C}, \mathrm{mGDD}_{0}$ 263 (Harrison et al. (2010). $V_{\mathrm{cmax}}$ and $R_{\mathrm{d}}$ values in both datasets are provided with 264 information about measurement temperatures. The values were adjusted both to $265 \mathrm{mGDD}_{0}$ and to $25^{\circ} \mathrm{C}$ using the relevant kinetic responses, as given by (Kattge \& 266 Knorr 2007) and Heskel et al. (2016). A global climatology of monthly temperature 267 provided by the Climatic Research Unit at a grid resolution of 10 arc minutes (CRU 268 CL2.0) (New et al. 2000) was used to provide estimates of $\mathrm{mGDD}_{0}$ for each location. 269 Thermal acclimation of $R_{\mathrm{d}}$ should apply to both $\mathrm{C}_{3}$ and $\mathrm{C}_{4}$ plants, but our theoretical 270 prediction of $V_{\text {cmax }}$ acclimation here is developed for $\mathrm{C}_{3}$ plants, and we did not include $271 \mathrm{C}_{4}$ species in our analysis.

\section{Statistical analysis}

273 To test our predictions of the acclimated thermal sensitivities of $R_{\mathrm{d}}$ and $V_{\text {cmax }}$ 274 quantitatively, the $R_{\mathrm{d}}$ and $V_{\text {cmax }}$ data (assessed at $\mathrm{mGDD}_{0}$ and $25^{\circ} \mathrm{C}$ ) were first 275 normalized with site-mean PPFD absorbed by leaves $\left(\mathrm{PPFD}_{\mathrm{L}}\right)$ before performing the 276 Ordinary Least Squares (OLS) regression against temperature. This normalization is 277 appropriate because $V_{\text {cmax }}$ is both predicted (see Appendix 1) and observed to vary in 278 proportion to PPFD (Niinemets \& Keenan, 2012). If it were omitted, the positive 279 effect of PPFD on $R_{\mathrm{d}}$ and $V_{\text {cmax }}$ would contribute to the fitted slope of $\mathrm{mGD}_{0}$ due to 280 the strong correlation between those two variables (Fig. S2). Site-mean PPFD $_{L}$ was 281 estimated from growing-season total incident PPFD at the top of the canopy $\left(\mathrm{PPFD}_{0}\right)$ :

$282 \quad \mathrm{PPFD}_{\mathrm{L}} \approx f \mathrm{PPFD}_{0} / L$

283 where $f$ is the fraction of incident PPFD absorbed by the canopy (from SeaWiFS data: 284 (Gobron et al. 2006; Kelley et al. 2013) and $L$ is the leaf area index estimated from 285 Beer's law:

$286 L \approx-(1 / k) \ln (1-f)$

287 with $k=0.5$ (Dong et al. (2017). This general approximation is used because we do 288 not have information on the light levels of species occupying different canopy strata. $289 \mathrm{PPFD}_{0}$ was calculated from CRU CL2.0 data using SPLASH (Davis et al. 2017). We 290 applied OLS linear regression of normalized (and natural log-transformed) $R_{\mathrm{d}}$ and $291 V_{\text {cmax }}$ values against $\mathrm{mGDD}_{0}$. The resulting slope coefficients are directly comparable 
292

293

294

295

with the thermal sensitivities predicted by theory. To check the impact of the PPFD normalization, we also performed regressions without it. Thermal acclimation of $R_{\mathrm{d}}$ and $V_{\text {cmax }}$ was further tested within PFTs, with species assigned to deciduous and evergreen needleleaf and broadleaf trees, deciduous and evergreen shrubs, and C3 herbaceous plants.

To test the hypothesis that $R_{\mathrm{d}}$ is mainly determined by $V_{\text {cmax }}$ rather than leaf or soil characteristics, we also included LMA and soil $\mathrm{pH}$ as additional predictors in the OLS regression above. LMA carries information on the structural component of plant leaves. Broadly speaking, higher soil pH indicates higher soil fertility (Jenny, 1994; Sinsabaugh \& Follstad Shah, 2012), and pH has been shown to influence $\chi$ (Wang et al. 2017b). These two covariates were selected to test any potential influences of leaf structure and soil nutrient availability, respectively, on $R_{\mathrm{d}}$. An estimate of soil $\mathrm{pH}$ for each location was extracted from the Harmonized World Soil Database (http://www.iiasa.ac.at). We applied Ordinary Least Squares (OLS) linear regression of $R_{\mathrm{d}}$ versus $V_{\text {cmax }}$ (standardized to $25^{\circ} \mathrm{C}$ and to $\mathrm{mGDD}_{0}$, without transformation) to estimate $b_{25}$ and $b$ directly from the fitted slopes. Relationships of $N_{\text {area }}$ with $V_{\text {cmax }}, R_{\mathrm{d}}$, and LMA were also tested by OLS multiple linear regression.

\section{Results}

\section{Sensitivity of acclimated $R_{d}$ and $V_{\text {cmax }}$ to growth temperature}

The predicted sensitivity of $V_{\text {cmax }}$ to growth temperature $\left(\beta_{\mathrm{aV}}\right)$ was $5.5 \% \mathrm{~K}^{-1}$ under standard environmental conditions. This value is identical with the fitted regression coefficient of normalized and transformed $V_{\text {cmax,tg }}$ against $\operatorname{mGDD}_{0}(5.6 \% \pm 0.3 \%$ : mean and $95 \%$ confidence interval, $R^{2}=0.50$ ) (Table 1, Fig. 2 ).

The prediction that $b$ should decline with temperature by $1.8 \% \mathrm{~K}^{-1}$ was consistent with the fitted regressions of the ratio of $R_{\mathrm{d}, \mathrm{tg}}$ to $V_{\text {cmax,tg; we observed a small but }}$ significant negative response of $b$ to growth temperature with a sensitivity of $2.0 \% \pm$ $0.3 \%$, while $b_{25}$ was indeed independent of $\mathrm{mGDD}_{0}$, as predicted (Table 1, Fig. 2). The fitted temperature response of $R_{\mathrm{d}, \mathrm{tg}}$ was consistently about $2 \%$ less steep than that of $V_{\text {cmax,tg }}$ (Table 1). 
321 The canonical value of $b_{25}=0.015$, as assumed in the photosynthesis model of Collatz 322 et al. (1991), was similar to the fitted value of $b_{25}=0.014 \pm 0.001$ based on the 323 regression of $R_{\mathrm{d}, 25}$ with respect to $V_{\mathrm{cmax}, 25}$ (Table 2). The regression lines of $R_{\mathrm{d}, \mathrm{tg}}$ with 324 respect to $V_{\text {cmax, tg }}$ when fitted to data in low $\left(T_{\mathrm{g}}<15^{\circ} \mathrm{C}\right)$, medium $\left(15^{\circ} \mathrm{C}<T_{\mathrm{g}}<25^{\circ} \mathrm{C}\right)$ 325 and high $\left(T_{\mathrm{g}}>25^{\circ} \mathrm{C}\right)$ temperature classes separately (Fig. S3) became shallower 326 toward higher temperature classes, also consistent with the prediction of a negative 327 response of $b$ to temperature.

328 The difference between the enzyme-kinetic sensitivities of $R_{\mathrm{d}}$ and $V_{\mathrm{cmax}}$ to temperature implies that the sensitivity of acclimated $R_{\mathrm{d}, \mathrm{tg}}$ to temperature $\left(\beta_{\mathrm{aR}}\right)$ is $1.8 \%$ 330 lower than that of $V_{\text {cmax,tg }}\left(\beta_{\mathrm{aV}}\right)$, implying a theoretical optimum rate of increase of $331 R_{\mathrm{d}, \mathrm{tg}}$ by $3.7 \%$ per degree. These theoretical responses are very close to those seen in 332 the observations, but rather more shallow than the $9.9 \%$ and $8.1 \% \mathrm{~K}^{-1}$ predicted for 333 the short-term responses of $V_{\mathrm{cmax}}$ and $R_{\mathrm{d}}$ from enzyme kinetics (Fig. 1). Theoretically 334 predicted values of the fractional sensitivities of acclimated $R_{\mathrm{d}, 25}\left(\beta_{\mathrm{aR} 25}\right)$ and $V_{\mathrm{cmax}, 25}$ $335\left(\beta_{\mathrm{aV} 25}\right)$ to temperature are negative $\left(-4.4 \% \mathrm{~K}^{-1}\right)$ and this is consistent with the 336 observed negative responses of $R_{\mathrm{d}, 25}$ and $V_{\mathrm{cmax}, 25}$ to temperature seen in the data 337 (Table 1). The observed negative response of $V_{\mathrm{cmax}, 25}$ to growth temperature is 338 identical $\left(-4.4 \pm 0.3 \% \mathrm{~K}^{-1}\right)$ to our theoretical prediction; the observed response of $339 R_{d}^{25}\left(-4.9 \pm 0.3 \% \mathrm{~K}^{-1}\right)$ is marginally larger than the prediction.

340 Regressions performed without PPFD-normalization (Table S1) showed temperature 341 responses with the same signs (positive for $V_{\text {cmax }}$ and $R_{d}$ at growth temperature, 342 negative at $25^{\circ} \mathrm{C}$ ) but slightly steeper (positive slopes) or shallower (negative slopes) 343 than in the main analyses - as expected due to the confounding of PPFD and 344 temperature effects, which normalization removes. $R^{2}$ values were consistently greater 345 in the main analyses, by $6-7 \%$ for $V_{\mathrm{cmax}}$ and $R_{d}$ at growth temperature and $11-16 \%$ for $346 V_{\text {cmax }}$ and $R_{d}$ at $25^{\circ} \mathrm{C}$.

347 Thermal acclimation of $V_{\text {cmax }}$ within PFTs was shown to be broadly consistent with 348 the universal relationships evident in the whole dataset (Table S2). Consistent with 349 Campbell et al. (2007) and Smith and Dukes (2017b), no significant differences in 350 thermal acclimation were found between PFTs with different leaf phenology 351 (evergreen versus deciduous), leaf form (needleleaf versus broadleaf), or life form 352 (trees versus shrubs versus herbaceous plants), although the fitted slope for evergreen 
353

broadleaf trees is higher than predicted. Thermal acclimation of $R_{\mathrm{d}}$ within PFTs shows more variable results. Evergreen broadleaf trees show higher than predicted thermal sensitivities of both $R_{\mathrm{d}}$ and $V_{\text {cmax }}$, but the fitted slope of their ratio versus growth temperature $(-1.8 \% \pm 0.4 \%)$ is identical with our predicted value $(-1.8 \%)$.

Microclimatic acclimation (Niinemets \& Keenan 2012), the likelihood that many measured leaves were at least partially shaded (Keenan \& Niinemets 2017), and genetic variations involving different plant strategies may all have contributed to the within-site variations in $R_{\mathrm{d}}$ and $V_{\text {cmax }}$ reflected in the vertical scatter of points in Fig. 2. The theory was applied here to predict variations in $R_{\mathrm{d}}$ and $V_{\text {cmax }}$ across sites, however, and as much as $45 \%$ and $60 \%$ variation in the community-mean $R_{\mathrm{d}, \mathrm{tg}}$ and $V_{\text {cmax,tg }}$ respectively could indeed be explained by growth temperature - with responses in quantitative agreement with predictions (Table S3).

\section{Relationships between dark respiration and carboxylation capacity}

We examined the relationships between $R_{\mathrm{d}}, V_{\mathrm{cmax}}$ and other factors, in order to test our hypothesis that $R_{\mathrm{d}}$ is principally determined by $V_{\text {cmax }}$. We found that measured $R_{\mathrm{d}}$ and $V_{\text {cmax }}$ were positively correlated in the datasets when normalized either to $\operatorname{mGDD}_{0}\left(R^{2}\right.$ $=0.25)$ or to a reference temperature of $25^{\circ} \mathrm{C}\left(R^{2}=0.16\right)($ Table 2$)$.

\section{Relationships of dark respiration and photosynthetic capacity to other variables}

Relationships of $R_{\mathrm{d}}$ and $V_{\text {cmax }}$ to $N_{\text {area }}$ were similar in strength when normalized to $25^{\circ} \mathrm{C}\left(R^{2}=0.14\right.$ and 0.12$)$ (Table 3$)$, but notably weaker when considered at growth temperature $\left(R^{2}=0.05\right.$ for $R_{\mathrm{d}, \mathrm{tg}}$ and 0.02 for $\left.V_{\mathrm{cmax}, \mathrm{tg}}\right)$. LMA and $V_{\mathrm{cmax}, 25}$ together accounted for $42 \%$ variation in $N_{\text {area }}$, but most of this explanatory power coming from LMA (Table 3). Similarly, LMA and $R_{\mathrm{d}, 25}$ together explained $41 \%$ variation in $N_{\text {area, }}$ but again most of this explanatory power is due to LMA (Table 3).

Considered on their own, neither LMA nor soil $\mathrm{pH}$ provided explanatory power in the variations of $R_{\mathrm{d}}$ and $V_{\text {cmax }}$ (whether at $25^{\circ} \mathrm{C}$ and growth temperature). The inclusion of one or the other in addition to $\mathrm{mGDD}_{0}$ as a predictor provided negligible increases in explained variance (Table S4). 


\section{Discussion}

Acclimation of leaf dark respiration follows the acclimation of carboxylation capacity

Farquhar et al. (1980) modelled instantaneous $R_{\mathrm{d}}$ at $25^{\circ} \mathrm{C}$ as a fixed fraction (1.1\%) of $V_{\text {cmax }}$ at $25^{\circ} \mathrm{C}$. Collatz et al. (1991) - citing Farquhar et al. (1980) - modelled $R_{\mathrm{d}}$ at $25^{\circ} \mathrm{C}$ as $1.5 \%$ of $V_{\text {cmax }}$ at $25^{\circ} \mathrm{C}$. Our results show that $R_{d}$ and $V_{\text {cmax }}$ are indeed closely related, whether standardized to growth temperature or to $25^{\circ} \mathrm{C}$, albeit with substantial scatter around the relationship. Moreover, the coefficient relating $R_{\mathrm{d}, 25}$ to $V_{\mathrm{cmax}, 25}$ estimated from this large global dataset $\left(b_{25}=0.014 \pm 0.01\right.$, Table 2$)$ is indistinguishable from the value of 0.015 used by Collatz et al. (1991). We also predict a slight negative response of $b$ to temperature due to the difference in the kinetic responses of $R_{\mathrm{d}}$ and $V_{\text {cmax }}$. This expectation is consistent with other studies (De Kauwe et al. 2016), and well supported by the finding here of a temperature effect in the regression of $b$ (estimated from the $R_{\mathrm{d}, \mathrm{tg}}$ to $V_{\text {cmax,tg }}$ ratio), but not in that of $b_{25}$ (estimated from the $R_{\mathrm{d}, 25}$ to $V_{\mathrm{cmax}, 25}$ ratio). The former provides a value of $\beta_{\mathrm{b}}$ close to our theoretical value of $1.8 \% \mathrm{~K}^{-1}$ (Table 1 ).

Atkin et al. (2015) indicated a decline in $b_{25}$ with increasing growth temperature. Their dataset that did not included the LCE data. To compare our analysis with that of Atkin et al. (2015), we assessed the response of $b_{25}$ to $\mathrm{mGDD}_{0}$ after excluding the LCE data. The response of $b_{25}$ to $\mathrm{mGDD}_{0}$ became significant $(p=0.0076)$ but its sensitivity $\left(\beta_{b 25}=-0.009 \pm 0.003\right)$ was much lower than that of $b\left(\beta_{b}=-0.024 \pm 0.003\right.$, $p<0.001)$. Atkin et al. (2015) considered the mean temperature of the warmest threemonth period as growth temperature (TWQ), whereas here all days with temperature above $0^{\circ} \mathrm{C}$ are accounted in the growing season - thus growth temperature by our definition $\left(\mathrm{mGDD}_{0}\right)$ is lower than TWQ, except for the low and high ends of the scale (Fig. S4). This methodological difference might have contributed to a slightly different conclusion regarding the temperature sensitivity of $b_{25}$.

Equation (1) would potentially allow predictions of the responses of $R_{\mathrm{d}}$ to other environmental determinants, including vapour pressure deficit, elevation and $\mathrm{CO}_{2}$, if these too are determined by the environmental responses of $V_{\text {cmax }}$. However, the data currently available do not allow us to test these predictions, due to either the limited environmental range covered by the data (such as elevation or $\mathrm{CO}_{2}$ ) or the strong 
412 correlations between potential explanatory variables (including light and temperature, 413 Fig. S2). Nevertheless, our theory provides a simple, first-principles approach to 414 predicting the thermal acclimation of $R_{\mathrm{d}}$ - one of the most important mechanisms 415 missing from current LSMs (Huntingford et al. 2017).

\section{Observed temperature responses are consistent with optimal plant function}

417 Many ecosystem models assume that $R_{\mathrm{d}}$ and $V_{\text {cmax }}$ respond to temperature following 418 the same functions that are routinely observed in short-term studies, disregarding 419 acclimation. Our results contradict this assumption. Optimally acclimated values of 420 both fluxes do increase with temperature, but much less steeply than expected from 421 short-term responses. Instead it appears that leaves 'discount' enzyme-kinetic 422 responses, so the two limiting photosynthetic rates remain similar under the 423 prevailing growth temperature. Positive temperature responses arise because of the 424 differential temperature sensitivities of two key quantities - the effective Michaelis425 Menten coefficient of Rubisco $(K)$ and the photorespiratory $\mathrm{CO}_{2}$ compensation point $426\left(\Gamma^{*}\right)$ - in the Farquhar et al. (1980) model. These predictions are supported by the 427 finding of temperature responses in the datasets evaluated here: that is, after the $R_{\mathrm{d}}$ 428 and $V_{\text {cmax }}$ values have been corrected to site-specific mean growing-season 429 temperatures, we find responses closely similar to the predicted optimal responses 430 (Fig. 2).

\section{The acclimated sensitivity of dark respiration to warming}

432 Acclimated $R_{\mathrm{d}}$ is predicted to increase with temperature by $3.7 \%$ per degree. This 433 long-term (weekly or longer) sensitivity is supported by the data and is smaller than 434 the enzyme-kinetic sensitivity of either $R_{\mathrm{d}}$ or $V_{\text {cmax }}$. This response is generally 435 conservative among PFTs.

436 Reich et al. (2016) conducted outdoor open-air warming experiments on ten boreal 437 and temperate tree species. Whole plants were warmed by $3.4^{\circ} \mathrm{C}$ during four growing 438 seasons, and showed even stronger acclimation of $R_{\mathrm{d}}$ and an acclimated sensitivity of 439 only $1.5 \%$ per degree. Slot and Kitajima (2015) indicated a value of $5.7 \%$ for the 440 temperature sensitivity of $R_{\mathrm{d}}$ based on a meta-analysis of 43 independent experiments 441 (mostly short-term, laboratory studies). Our theory predicts $\beta_{\mathrm{aR}}$ as $3.7 \%$ per degree 442 warming, intermediate between the values found by Reich et al. (2016) and Slot and 
443 Kitajima (2015). In a study that acclimated plants for seven days, Smith and Dukes 444 (2017b) found even less acclimation of $R_{\mathrm{d}}$ than either of those studies. The differences 445 among these three studies suggest that the time scale of exposure to elevated 446 temperatures might play a role.

447 Heskel et al. (2016) presented data from different biomes that can be compared to our 448 predictions of the acclimation of $R_{\mathrm{d}}$. We can estimate $a$ in equation (3) by 449 rearrangement, with $T_{\text {ref }}=25^{\circ} \mathrm{C}$ :

$$
=\ln b_{25}+\ln V_{\mathrm{cmax}, 25}-0.1012 \times 25-0.0005 \times 25^{2}
$$

452 The thermal sensitivity of $a$ should therefore be the same as that of $\beta_{\mathrm{aR} 25}$. Its decline 453 from tundra to tropical forests (Heskel et al., 2016) is the result of $R_{\mathrm{d}}$ acclimation to 454 growth temperature (Slot \& Kitajima 2015; Vanderwel et al. 2015). Our theory 455 estimates $a$ independently: $a=-2.502$ when $V_{\text {cmax }, 25}=50 \mu \mathrm{mol} \mathrm{m}^{-2} \mathrm{~s}^{-1}$ (i.e. equivalent 456 to $R_{\mathrm{d}, 25}=1.4 \mu \mathrm{mol} \mathrm{m} \mathrm{m}^{-1}$ ), or $a=-1.407$ when $V_{\mathrm{cmax}, 25}=150 \mu \mathrm{mol} \mathrm{m} \mathrm{s}^{-1}$ (i.e. 457 equivalent to $R_{\mathrm{d}, 25}=4.2 \mu \mathrm{mol} \mathrm{m}^{-2} \mathrm{~s}^{-1}$ ). These values are similar to those derived from 458 observations by Heskel et al. (2016): lower for warm biomes (e.g. $a=-2.749$ for 459 lowland tropical rainforest), where we would expect relatively low $V_{\text {cmax,25; }}$ and 460 higher for cold biomes (e.g. $a=-1.604$ for tundra), where we would expect relatively

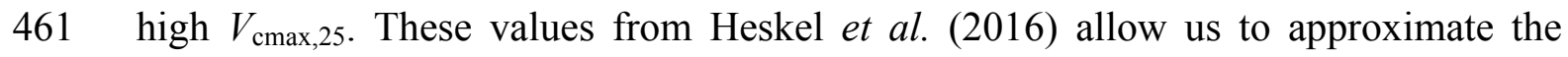
462 thermal sensitivity of $a$ as $-4.6 \% \mathrm{~K}^{-1}$, assuming a growth temperature range of $25^{\circ} \mathrm{C}$ 463 from tundra to rainforest - very close to our theoretical prediction of $\beta_{\mathrm{aR} 25}=-4.4 \% \mathrm{~K}^{-}$ 4641.

\section{Relationships of respiration and photosynthetic capacity with leaf $N$}

466 It is often assumed that $R_{\mathrm{d}}$ and $V_{\text {cmax }}$ (assessed at standard temperature) are closely 467 related to $N_{\text {area}}$, and empirical studies have reported relationships of both quantities to $468 N_{\text {area }}$ (Reich et al. 1998; Meir et al. 2001; Wright et al. 2004; Atkin et al. 2015). 469 Correlation of both $R_{\mathrm{d}, 25}$ and $V_{\mathrm{cmax}, 25}$ with $N_{\text {area }}$ is expected because of the significant 470 fraction of $N_{\text {area }}$ that is contained in Rubisco and other photosynthetic proteins, and 471 the functional relationship between $R_{\mathrm{d}}$ and $V_{\text {cmax }}$. ( $N_{\text {area }}$ should always be compared to $472 R_{\mathrm{d}}$ and $V_{\text {cmax }}$ corrected to a common temperature, because the amount of "metabolic" 
$473 \mathrm{~N}$ required to achieve a given catalytic activity is strongly dependent on temperature.)

474 We found the expected positive relationships of $R_{\mathrm{d}, 25}$ and $V_{\mathrm{cmax}, 25}$ to $N_{\text {area }}$, but they 475 were not strong $\left(R^{2}=0.11\right.$ and 0.14 , Table 3). Onoda et al. (2017) noted the 476 substantial fraction of leaf $\mathrm{N}$ allocated to cell walls, in addition to the fraction 477 contained in photosynthetic proteins. Our finding that far more variation in $N_{\text {area }}$ can 478 be explained by LMA than by $V_{\text {cmax }}$ (Table 3 ) suggests that the structural (cell wall) 479 component of $N_{\text {area }}$ is important (see also (Dong et al. 2017). $N_{\text {area }}$ is thus not a 480 straightforward predictor of either $V_{\text {cmax }}$ or $R_{\mathrm{d}}$, but rather contains both a metabolic

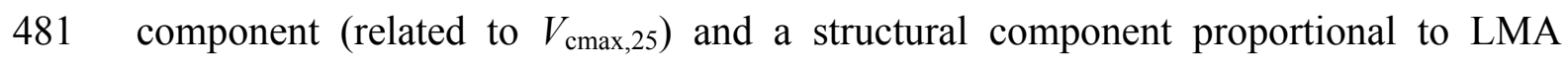
482 (Dong et al., 2017). Mass-based quantities show a similar pattern (Table S5) with 483 more variation in $N_{\text {mass }}$ explained by LMA than by $V_{\text {cmax }}$. However, LMA is 484 negatively related to $N_{\text {mass, }}$, which indicates that the concentration of $\mathrm{N}$ in bulk leaf 485 tissue is lower than that in the photosynthetic machinery.

486 The coordination hypothesis implies that $V_{\mathrm{cmax}}$, and therefore also the metabolic 487 component of $N_{\text {area, }}$, should be determined by photosynthetic demand - rather than $488 V_{\text {cmax }}$ being determined by $N_{\text {area }}$, as is currently assumed in many models. This point is 489 further addressed by (Maire et al. 2012; Dong et al. 2017), who noted that the co490 ordination hypothesis predicts an optimal value for metabolic $N_{\text {area }}$ on the basis of 491 environmental conditions alone. The empirical $V_{\text {cmax }}-N_{\text {area }}$ relationship has been 492 widely interpreted as a manifestation of ' $\mathrm{N}$ limitation' of photosynthesis at the leaf 493 level (Luo et al. 2004), and underpins the use of $N_{\text {area }}$ as a predictor of photosynthetic 494 capacity in models (Ciais et al. 2014). An alternative interpretation is that leaf 495 metabolic $\mathrm{N}$ depends primarily on the demand for photosynthetic capacity, which is 496 set by the local environment and in turn determines the capacity for dark respiration; 497 while $\mathrm{N}$ availability primarily influences the allocation of carbon to leaves versus 498 other organs (LeBauer \& Treseder 2008; Poorter et al. 2012).

\section{Conclusions}

500 The observed thermal acclimation of $R_{\mathrm{d}}$ follows the optimization of $V_{\text {cmax }}$ as predicted 501 by the coordination hypothesis. This acclimation dampens the enzyme-kinetic 502 response of $R_{\mathrm{d}}$ to temperature and shows little influence from other factors. The 503 discrepancy between thermal acclimation and enzyme-kinetic thermal response 504 implies that both $R_{\mathrm{d}}$ or $V_{\text {cmax }}$, converted to $25^{\circ} \mathrm{C}$ or any other arbitrarily chosen 
reference temperature, must decline with plant growth temperature. These principles would be straightforward to incorporate in an LSM framework, as an alternative to PFT-based schemes in current use. The theory provides an explanation for the observed correlations between $N_{\text {area }}, V_{\text {cmax }}$ and $R_{\mathrm{d}}$ that differs from the common assumption that $N_{\text {area }}$ determines $V_{\text {cmax }}$ and $R_{\mathrm{d}}$, and supports an alternative perspective on the coupling between the terrestrial carbon and nitrogen cycles.

\section{References}

Ainsworth, E.A. \& Long, S.P. (2005). What have we learned from 15 years of free air $\mathrm{CO}_{2}$ enrichment (FACE)? A meta - analytic review of the responses of photosynthesis, canopy properties and plant production to rising $\mathrm{CO}_{2}$. New Phytologist, 165, $351-372$.

Amthor, J.S. (2000). The McCree-de Wit-Penning de Vries-Thornley respiration paradigms: 30 years later. Annals of botany, 86, 1-20.

Aspinwall, M.J., Drake, J.E., Campany, C., Vårhammar, A., Ghannoum, O., Tissue, D.T. et al. (2016). Convergent acclimation of leaf photosynthesis and respiration to prevailing ambient temperatures under current and warmer climates in Eucalyptus tereticornis. New Phytologist, 212, 354-367.

Atkin, O.K., Bloomfield, K.J., Bahar, N.H., Griffin, K.L., Heskel, M.A., Huntingford, C. et al. (2017). Leaf Respiration in Terrestrial Biosphere Models. In: Plant Respiration: Metabolic Fluxes and Carbon Balance (ed. Tcherkez, G). Springer-Nature: Netherlands, pp. 107-142.

Atkin, O.K., Bloomfield, K.J., Reich, P.B., Tjoelker, M.G., Asner, G.P., Bonal, D. et al. (2015). Global variability in leaf respiration in relation to climate, plant functional types and leaf traits. New Phytologist, 206, 614-636.

Atkin, O.K., Millar, A.H., Gardeström, P. \& Day, D.A. (2000). Photosynthesis, carbohydrate metabolism and respiration in leaves of higher plants. In: Photosynthesis. Springer, pp. 153-175.

Atkin, O.K., Scheurwater, I. \& Pons, T.L. (2007). Respiration as a percentage of daily photosynthesis in whole plants is homeostatic at moderate, but not high, growth temperatures. New Phytologist, 174, 367-380.

Atkin, O.K. \& Tjoelker, M.G. (2003). Thermal acclimation and the dynamic response of plant respiration to temperature. Trends in plant science, 8, 343-351.

Bernacchi, C., Singsaas, E., Pimentel, C., Portis Jr, A. \& Long, S. (2001). Improved temperature response functions for models of Rubisco - limited photosynthesis. Plant, Cell \& Environment, 24, 253 - 259.

Blonder, B., Salinas, N., Bentley, L.P., Shenkin, A., Porroa, P.O.C., Tejeira, Y.V. et al. (2017). Predicting trait - environment relationships for venation networks along an Andes - Amazon elevation gradient. Ecology, 98, 1239 - 1255.

Booth, B.B., Jones, C.D., Collins, M., Totterdell, I.J., Cox, P.M., Sitch, S. et al. (2012). High sensitivity of future global warming to land carbon cycle processes. Environmental Research Letters, 7, 024002.

Bouma, T.J. (2005). Understanding plant respiration: separating respiratory components versus a process-based approach. In: Plant respiration. Springer, pp. 177-194. 
Campbell, C., Atkinson, L., Zaragoza - Castells, J., Lundmark, M., Atkin, O. \& Hurry, V. (2007). Acclimation of photosynthesis and respiration is asynchronous in response to changes in temperature regardless of plant functional group. New Phytologist, 176, 375 - 389.

Cannell, M. \& Thornley, J. (2000). Modelling the components of plant respiration: some guiding principles. Annals of Botany, 85, 45-54.

Ciais, P., Sabine, C., Bala, G., Bopp, L., Brovkin, V., Canadell, J. et al. (2014). Carbon and other biogeochemical cycles. Climate change 2013: the physical science basis. Contribution of Working Group I to the Fifth Assessment Report of the Intergovernmental Panel on Climate Change, 465-570.

Collatz, G.J., Ball, J.T., Grivet, C. \& Berry, J.A. (1991). Physiological and environmental regulation of stomatal conductance, photosynthesis and transpiration: a model that includes a laminar boundary layer. Agricultural and Forest meteorology, 54, 107-136.

Collatz, G.J., Berry, J.A., Farquhar, G.D. \& Pierce, J. (1990). The relationship between the Rubisco reaction mechanism and models of photosynthesis. Plant, Cell \& Environment, 13, 219-225.

Cowan, I.R. (1986). Economics of carbon fixation in higher plants. In: On the economy of plant form and function (ed. Givnish, TJ). Cambridge University Press Cambridge, pp. 133-170.

Cox, P.M., Betts, R.A., Jones, C.D., Spall, S.A. \& Totterdell, I.J. (2000). Acceleration of global warming due to carbon-cycle feedbacks in a coupled climate model. Nature, 408, 184-187.

Davis, T.W., Prentice, I.C., Stocker, B.D., Thomas, R.T., Whitley, R.J., Wang, H. et al. (2017). Simple process-led algorithms for simulating habitats (SPLASH v. 1.0): robust indices of radiation, evapotranspiration and plant-available moisture. Geoscientific Model Development, 10, 689.

De Kauwe, M.G., Lin, Y.-S., Wright, I.J., Medlyn, B.E., Crous, K.Y., Ellsworth, D.S. et al. (2016). A test of the 'one-point method' for estimating maximum carboxylation capacity from field-measured, light-saturated photosynthesis. New Phytologist, 210, 1130-1144.

Dewar, R., Mauranen, A., Mäkelä, A., Hölttä, T., Medlyn, B. \& Vesala, T. (2018). New insights into the covariation of stomatal, mesophyll and hydraulic conductances from optimization models incorporating nonstomatal limitations to photosynthesis. New Phytologist, 217, 571-585.

Dong, N., Prentice, I.C., Evans, B.J., Caddy-Retalic, S., Lowe, A.J. \& Wright, I.J. (2017). Leaf nitrogen from first principles: field evidence for adaptive variation with climate. Biogeosciences, 14, 481-495.

Drake, J.E., Tjoelker, M.G., Aspinwall, M.J., Reich, P.B., Barton, C.V., Medlyn, B.E. et al. (2016). Does physiological acclimation to climate warming stabilize the ratio of canopy respiration to photosynthesis? New Phytologist, 211, 850-863.

Farquhar, G.D., Buckley, T.N. \& Miller, J.M. (2002). Optimal stomatal control in relation to leaf area and nitrogen content. Silva Fennica, 36, 625-637.

Farquhar, G.D., von Caemmerer, S.v. \& Berry, J. (1980). A biochemical model of photosynthetic $\mathrm{CO}_{2}$ assimilation in leaves of $\mathrm{C}_{3}$ species. Planta, 149, 78-90.

Friedlingstein, P., Meinshausen, M., Arora, V.K., Jones, C.D., Anav, A., Liddicoat, S.K. et al. (2014). Uncertainties in CMIP5 climate projections due to carbon cycle feedbacks. Journal of Climate, 27, 511-526. 
Gifford, R.M. (2003). Plant respiration in productivity models: conceptualisation, representation and issues for global terrestrial carbon-cycle research. Functional Plant Biology, 30, 171-186.

Givnish, T.J. (1986a). On the economy of plant form and function. Cambridge University Press, Cambridge.

Givnish, T.J. (1986b). Optimal stomatal conductance, allocation of energy between leaves and roots, and the marginal cost of transpiration. In: On the economy of plant form and function (ed. Givnish, TJ). Cambridge University Press Cambridge, pp. 25-55.

Gobron, N., Pinty, B., Taberner, M., Mélin, F., Verstraete, M. \& Widlowski, J.-L. (2006). Monitoring the photosynthetic activity of vegetation from remote sensing data. Advances in Space Research, 38, 2196-2202.

Harrison, S.P., Prentice, I.C., Barboni, D., Kohfeld, K.E., Ni, J. \& Sutra, J.P. (2010). Ecophysiological and bioclimatic foundations for a global plant functional classification. Journal of Vegetation Science, 21, 300-317.

Haxeltine, A. \& Prentice, I.C. (1996). A general model for the light-use efficiency of primary production. Functional Ecology, 10, 551-561.

Heskel, M.A., O’Sullivan, O.S., Reich, P.B., Tjoelker, M.G., Weerasinghe, L.K., Penillard, A. et al. (2016). Convergence in the temperature response of leaf respiration across biomes and plant functional types. Proceedings of the National Academy of Sciences, 113, 3832-3837.

Hoefnagel, M., Atkin, O. \& Wiskich, J. (1998). Interdependence between chloroplasts and mitochondria in the light and the dark. Biochimica Et Biophysica ActaBioenergetics, 1366, 235-255.

Huntingford, C., Atkin, O.K., Heskel, M.A., Martinez-de la Torre, A., Harper, A.B., Bloomfield, K.J. et al. (2017). Implications of improved representation of plant respiration in a changing climate. Nature Communications, 8, 1602.

Huntingford, C., Zelazowski, P., Galbraith, D., Mercado, L.M., Sitch, S., Fisher, R. et al. (2013). Simulated resilience of tropical rainforests to $\mathrm{CO}_{2}$-induced climate change. Nature Geoscience, 6, 268.

Kattge, J. \& Knorr, W. (2007). Temperature acclimation in a biochemical model of photosynthesis: a reanalysis of data from 36 species. Plant, cell \& environment, 30, 1176-1190.

Keenan, T.F. \& Niinemets, Ü. (2017). Global leaf trait estimates biased due to plasticity in the shade. Nature plants, 3, 16201.

Keenan, T.F., Prentice, I.C., Canadell, J.G., Williams, C.A., Wang, H., Raupach, M. et al. (2016). Recent pause in the growth rate of atmospheric $\mathrm{CO}_{2}$ due to enhanced terrestrial carbon uptake. Nature communications, 7, 13428.

Kelley, D., Prentice, I.C., Harrison, S., Wang, H., Simard, M., Fisher, J. et al. (2013). A comprehensive benchmarking system for evaluating global vegetation models. Biogeosciences, 10, 3313-3340.

Kikuzawa, K., Onoda, Y., Wright, I.J. \& Reich, P.B. (2013). Mechanisms underlying global temperature - related patterns in leaf longevity. Global Ecology and Biogeography, 22, 982 - 993.

Lin, Y.-S., Medlyn, B.E., Duursma, R.A., Prentice, I.C., Wang, H., Baig, S. et al. (2015). Optimal stomatal behaviour around the world. Nature Climate Change, 5, 459-464.

Luo, Y., Su, B., Currie, W.S., Dukes, J.S., Finzi, A., Hartwig, U. et al. (2004). Progressive nitrogen limitation of ecosystem responses to rising atmospheric carbon dioxide. AIBS Bulletin, 54, 731-739. 
660

661

662

663

664

665

666

667

668

669

670

671

672

673

674

675

676

677

678

679

680

681

682

683

684

685

686

687

688

689

690

691

692

693

694

695

696

Maire, V., Martre, P., Kattge, J., Gastal, F., Esser, G., Fontaine, S. et al. (2012). The coordination of leaf photosynthesis links $\mathrm{C}$ and $\mathrm{N}$ fluxes in $\mathrm{C}_{3}$ plant species. PloS one, 7, e38345.

Marquet, P.A., Allen, A.P., Brown, J.H., Dunne, J.A., Enquist, B.J., Gillooly, J.F. et al. (2014). On theory in ecology. BioScience, 64, 701-710.

Meir, P., Grace, J. \& Miranda, A. (2001). Leaf respiration in two tropical rainforests: constraints on physiology by phosphorus, nitrogen and temperature. Functional Ecology, 15, 378-387.

New, M., Hulme, M. \& Jones, P. (2000). Representing Twentieth-Century SpaceTime Climate Variability. Part II: Development of 1901-96 Monthly Grids of Terrestrial Surface Climate. Journal of Climate, 13, 2217-2238.

Niinemets, Ü. \& Keenan, T. (2012). Measures of light in studies on light-driven plant plasticity in artificial environments. Frontiers in plant science, 3, 156.

Noguchi, K. \& Yoshida, K. (2008). Interaction between photosynthesis and respiration in illuminated leaves. Mitochondrion 8, 87-99.

Onoda, Y., Wright, I.J., Evans, J.R., Hikosaka, K., Kitajima, K., Niinemets, Ü. et al. (2017). Physiological and structural tradeoffs underlying the leaf economics spectrum. New Phytologist, 214, 1447-1463.

Reich, P.B., Sendall, K.M., Stefanski, A., Wei, X., Rich, R.L. \& Montgomery, R.A. (2016). Boreal and temperate trees show strong acclimation of respiration to warming. Nature, 531, 633-636.

Reich, P.B., Walters, M.B., Ellsworth, D.S., Vose, J.M., Volin, J.C., Gresham, C. et al. (1998). Relationships of leaf dark respiration to leaf nitrogen, specific leaf area and leaf life-span: a test across biomes and functional groups. Oecologia, $114,471-482$.

Rogers, A. (2014). The use and misuse of $V_{c, \max }$ in Earth System Models. Photosynthesis Research, 119, 15-29.

Scafaro, A.P., Xiang, S., Long, B.M., Bahar, N.H., Weerasinghe, L.K., Creek, D. et al. (2017). Strong thermal acclimation of photosynthesis in tropical and temperate wet-forest tree species: the importance of altered Rubisco content. Global Change Biology, 23, 2783-2800.

Slot, M. \& Kitajima, K. (2015). General patterns of acclimation of leaf respiration to elevated temperatures across biomes and plant types. Oecologia, 177, 885900.

Smith, N.G. \& Dukes, J.S. (2013). Plant respiration and photosynthesis in global scale models: incorporating acclimation to temperature and $\mathrm{CO} 2$. Global Change Biology, 19, $45-63$.

Smith, N.G. \& Dukes, J.S. (2017a). LCE: leaf carbon exchange data set for tropical, temperate, and boreal species of North and Central America. Ecology, 98, 2978-2978.

Smith, N.G. \& Dukes, J.S. (2017b). Short - term acclimation to warmer temperatures accelerates leaf carbon exchange processes across plant types. Global change biology, 23, 4840 - 4853.

Smith, N.G., Malyshev, S.L., Shevliakova, E., Kattge, J. \& Dukes, J.S. (2016). Foliar temperature acclimation reduces simulated carbon sensitivity to climate. Nature Climate Change, 6, 407-411.

Tcherkez, G., Boex-Fontvieille, E, Mahe, A, Hodges, M (2012). Respiratory carbon fluxes in leaves. Current Opinion in Plant Biology 15, 308-314.

Tilman, D. (1999). The ecological consequences of changes in biodiversity: a search for general principles. Ecology, 80, 1455-1474. 
Togashi, F.H., Prentice, I.C., Atkin, O.K., Macfarlane, C., Prober, S.M., Bloomfield, K.J. et al. (2018). Thermal acclimation of leaf photosynthetic traits in an evergreen woodland, consistent with the co-ordination hypothesis. Biogeosciences, 15, 3461-3474.

Vanderwel, M.C., Slot, M., Lichstein, J.W., Reich, P.B., Kattge, J., Atkin, O.K. et al. (2015). Global convergence in leaf respiration from estimates of thermal acclimation across time and space. New Phytologist, 207, 1026-1037.

Wang, H., Prentice, I. \& Davis, T. (2014). Biophsyical constraints on gross primary production by the terrestrial biosphere. Biogeosciences, 11, 5987-6001.

Wang, H., Prentice, I.C., Davis, T.W., Keenan, T.F., Wright, I.J. \& Peng, C. (2017a). Photosynthetic responses to altitude: an explanation based on optimality principles. New Phytologist, 213, 976-982.

Wang, H., Prentice, I.C., Keenan, T.F., Davis, T.W., Wright, I.J., Cornwell, W.K. et al. (2017b). Towards a universal model for carbon dioxide uptake by plants. Nature Plants, 3, 734-741.

Weng, E., Farrior, C.E., Dybzinski, R. \& Pacala, S.W. (2017). Predicting vegetation type through physiological and environmental interactions with leaf traits: Evergreen and deciduous forests in an earth system modeling framework. Global change biology, 23, 2482-2498.

Wolf, A., Anderegg, W.R. \& Pacala, S.W. (2016). Optimal stomatal behavior with competition for water and risk of hydraulic impairment. Proceedings of the National Academy of Sciences, 113, E7222-E7230.

Wright, I.J., Reich, P.B., Atkin, O.K., Lusk, C.H., Tjoelker, M.G. \& Westoby, M. (2006). Irradiance, temperature and rainfall influence leaf dark respiration in woody plants: evidence from comparisons across 20 sites. New Phytologist, 169, 309-319.

Wright, I.J., Reich, P.B. \& Westoby, M. (2003). Least - cost input mixtures of water and nitrogen for photosynthesis. The American Naturalist, 161, 98-111.

Wright, I.J., Reich, P.B., Westoby, M., Ackerly, D.D., Baruch, Z., Bongers, F. et al. (2004). The worldwide leaf economics spectrum. Nature, 428, 821-827.

$\mathrm{Xu}, \mathrm{X}$. , Medvigy, D., Joseph Wright, S., Kitajima, K., Wu, J., Albert, L.P. et al. (2017). Variations of leaf longevity in tropical moist forests predicted by a trait - driven carbon optimality model. Ecology letters, 20, 1097 - 1106.

Ziehn, T., Kattge, J., Knorr, W. \& Scholze, M. (2011). Improving the predictability of global $\mathrm{CO}_{2}$ assimilation rates under climate change. Geophysical Research Letters, 38, L10404. 
735 Table 1: Summary of Ordinary Least-Squares regressions for natural log-transformed 736 area-based leaf dark respiration $\left(R_{\mathrm{d}}\right)$, area-based maximum carboxylation rate $\left(V_{\mathrm{cmax}}\right)$ 737 and their ratio as a function of growth temperature. Both $R_{\mathrm{d}}$ and $V_{\text {cmax }}$ have been 738 standardized to growth temperature $\left(R_{\mathrm{d}, \mathrm{tg}}\right.$ and $\left.V_{\text {cmax,tg }}\right)$ and to $25{ }^{\circ} \mathrm{C}\left(R_{\mathrm{d}, 25}\right.$ and $\left.V_{\mathrm{cmax}, 25}\right)$, 739 and normalized by site-mean leaf absorbed photosynthetic photon flux density. The 740 fitted coefficient and its confidence interval are shown together with the 741 corresponding theoretical expectation, the intercept (mean \pm standard error), the 742 coefficient of determination $\left(r^{2}\right)$ and the degrees of freedom $(d f)$. Non-significant 743 coefficients are shown in grey.

744

\begin{tabular}{|c|c|c|c|c|c|c|c|}
\hline \multirow[t]{2}{*}{ Quantity } & \multirow[t]{2}{*}{$\begin{array}{r}\text { Theoretical } \\
\text { value }\end{array}$} & \multirow[t]{2}{*}{$\begin{array}{r}\text { Fitted } \\
\text { coefficient }\end{array}$} & \multicolumn{2}{|c|}{ Confidence intervals } & \multirow[t]{2}{*}{ Intercept } & \multirow[t]{2}{*}{$r^{2}$} & \multirow[t]{2}{*}{$d f$} \\
\hline & & & $2.5 \%$ & $97.5 \%$ & & & \\
\hline$R_{\mathrm{d}, \mathrm{tg}}$ & 0.037 & 0.033 & 0.029 & 0.038 & $-9.335 \pm 0.051$ & 0.34 & 1245 \\
\hline$V_{\text {cmax }, \mathrm{tg}}$ & 0.055 & 0.056 & 0.050 & 0.061 & $-6.386 \pm 0.054$ & 0.50 & 1009 \\
\hline$R_{\mathrm{d}, \mathrm{tg}} / V_{\text {cmax }, \mathrm{tg}}$ & -0.018 & -0.020 & -0.026 & -0.015 & $-2.916 \pm 0.060$ & 0.05 & 1007 \\
\hline$R_{\mathrm{d}, 25}$ & -0.044 & -0.049 & -0.054 & -0.045 & $-7.261 \pm 0.052$ & 0.25 & 1245 \\
\hline$V_{\text {cmax }, 25}$ & -0.044 & -0.044 & -0.049 & -0.038 & $-3.907 \pm 0.054$ & 0.26 & 1009 \\
\hline$R_{\mathrm{d}, 25} / V_{\mathrm{cmax}, 25}$ & 0 & -0.005 & -0.010 & 0.001 & $-3.317 \pm 0.060$ & 0.00 & 1007 \\
\hline
\end{tabular}


745 Table 2: Summary statistics for Ordinary Least Squares regressions of area-based leaf 746 dark respiration $\left(R_{\mathrm{d}}\right)$ against area-based maximum carboxylation rate $\left(V_{\text {cmax }}\right)$ assessed 747 at growth temperature and at $25^{\circ} \mathrm{C}$. The fitted slopes and intercept are shown together 748 with their standard errors (SE), the coefficient of determination $\left(r^{2}\right)$ and the degrees of 749 freedom $(d f)$.

750

\begin{tabular}{llllllll}
\hline Formula & Slope & SE & Intercept & SE & $r^{2}$ & $p$ value & $d f$ \\
\hline$R_{\mathrm{d}, \mathrm{tg}} \sim V_{\text {cmax }, \mathrm{tg}}$ & 0.015 & 0.001 & 0.495 & 0.026 & 0.25 & $<0.05$ & 1007 \\
$R_{\mathrm{d}, 25} \sim V_{\mathrm{cmax}, 25}$ & 0.014 & 0.001 & 0.787 & 0.048 & 0.16 & $<0.05$ & 1007 \\
\hline
\end{tabular}


751 Table 3: Summary statistics for Ordinary Least Squares regressions of area-based leaf 752 nitrogen content against area-based leaf dark respiration $\left(R_{\mathrm{d}}\right)$, area-based leaf 753 maximum capacity of carboxylation $\left(V_{\mathrm{cmax}}\right)$ assessed at growth temprature and $25^{\circ} \mathrm{C}$, 754 and leaf mass per area (LMA). The fitted slopes (mean \pm standard error) are shown 755 together with the intercept (mean \pm standard error), the adjusted coefficient of 756 determination $\left(r^{2}\right)$ and the degrees of freedom $(d f)$. All variables were natural-log 757 transformed.

758

\begin{tabular}{|c|c|c|c|c|c|c|c|}
\hline \multicolumn{5}{|c|}{ Coefficient } & \multirow[t]{2}{*}{ Intercept } & \multirow[t]{2}{*}{$r^{2}$} & \multirow[t]{2}{*}{$d f$} \\
\hline$V_{\text {cmax,tg }}$ & $V_{\text {cmax }, 25}$ & $R_{\mathrm{d}, \mathrm{tg}}$ & $R_{\mathrm{d}, 25}$ & LMA & & & \\
\hline $0.083 \pm 0.019$ & & & & & $0.409 \pm 0.059$ & 0.02 & 935 \\
\hline \multirow[t]{7}{*}{$0.058 \pm 0.015$} & & & & $0.491 \pm 0.021$ & $-1.849 \pm 0.107$ & 0.39 & 934 \\
\hline & $0.242 \pm 0.022$ & & & & $-0.199 \pm 0.081$ & 0.12 & 935 \\
\hline & $0.148 \pm 0.018$ & & & $0.458 \pm 0.021$ & $-2.055 \pm 0.106$ & 0.42 & 934 \\
\hline & & $0.177 \pm 0.022$ & & & $0.677 \pm 0.015$ & 0.05 & 1165 \\
\hline & & $0.107 \pm 0.018$ & & $0.508 \pm 0.020$ & $-1.724 \pm 0.097$ & 0.38 & 1164 \\
\hline & & & $0.301 \pm 0.022$ & & $0.590 \pm 0.013$ & 0.14 & 1165 \\
\hline & & & $0.174 \pm 0.019$ & $0.471 \pm 0.020$ & $-1.606 \pm 0.097$ & 0.41 & 1164 \\
\hline
\end{tabular}


Figure 1: Schematic of the thermal sensitivities of area-based maximum capacity of 760 carboxylation $\left(V_{\text {cmax }}\right)$ and leaf dark respiration $\left(R_{\mathrm{d}}\right) . \beta_{\mathrm{av}}$ : the acclimated thermal 761 sensitivity of $V_{\text {cmax }}$ assessed at growth temperature $\left(T_{\mathrm{g}}\right) . \beta_{\mathrm{aR}}$ : the acclimated thermal 762 sensitivity of $R_{\mathrm{d}}$ assessed at growth temperature. $\beta_{\mathrm{iv}}$ : the kinetic thermal sensitivity of $763 V_{\text {cmax }}$ assessed at growth temperature. $\beta_{\mathrm{iR}}$ : the kinetic thermal sensitivity of $R_{\mathrm{d}}$ assessed 764 at growth temperature. $\beta_{\mathrm{av} 25}$ : the acclimated thermal sensitivity of $V_{\text {cmax }}$ assessed at $76525^{\circ} \mathrm{C}$. $\beta_{\mathrm{aR} 25}$ : the acclimated thermal sensitivity of $R_{\mathrm{d}}$ assessed at $25^{\circ} \mathrm{C}$. $\beta_{\mathrm{b}}$ : the thermal 766 sensitivity of the ratio of $R_{\mathrm{d}}$ to $V_{\text {cmax }}$ assessed at growth temperature. $V_{\text {cmax }}$ and $R_{\mathrm{d}}$ are 767 assessed at growth temperature $\left(V_{\text {cmax,tg }}\right.$ and $\left.R_{\mathrm{d}, \mathrm{tg}}\right)$ as a starting point, $25^{\circ} \mathrm{C}$ as the 768 common practice ( $V_{\mathrm{cmax}, 25}$ and $\left.R_{\mathrm{d}, 25}\right)$ and a higher growth temperature $\left(T_{\mathrm{g}}{ }^{\prime}\right)$ for the 769 acclimation behaviour ( $V^{\prime}{ }_{\mathrm{cmax}, \mathrm{tg}}, R_{\mathrm{d}, \mathrm{tg}}^{\prime}, V^{\prime}{ }_{\mathrm{cmax}, 25}$ and $\left.R_{\mathrm{d}, 25}\right)$ to warming.

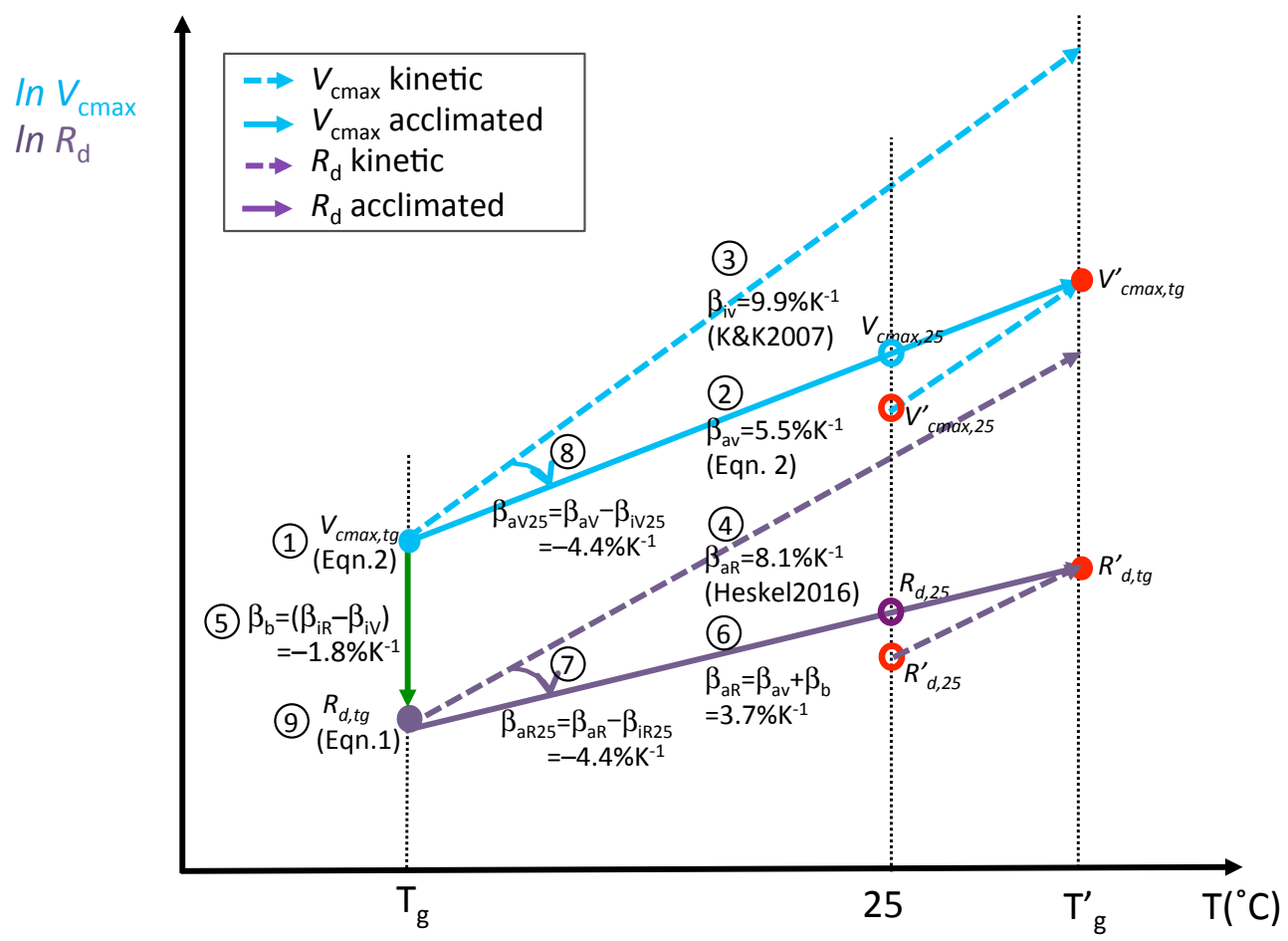


771 Figure 2: Natural log-transformed light-normalized leaf dark respiration $\left(R_{\mathrm{d}}\right)$, 772 maximum carboxylation rates $\left(V_{\mathrm{cmax}}\right)$ and their ratio, standardized to growth 773 temperature $\left(R_{\mathrm{d}, \mathrm{tg}}, \quad V_{\text {cmax,tg}}, \quad b: \quad R_{\mathrm{d}, \mathrm{tg}} / V_{\mathrm{cmax}, \mathrm{tg}}\right)$ and to $25^{\circ} \mathrm{C} \quad\left(R_{\mathrm{d}, 25}, V_{\mathrm{cmax}, 25}, b_{2}\right.$ : $\left.774 R_{\mathrm{d}, 25} / V_{\mathrm{cmax}, 25}\right)$, as a function of growth temperature $\left(\mathrm{mGDD}_{0}\right)$. Solid blue lines are the 775 fitted lines from Ordinary Least Squares regressions. Solid black lines are theoretical 776 predictions. Dashed lines represent the instantaneous temperature response based on 777 enzyme kinetics.
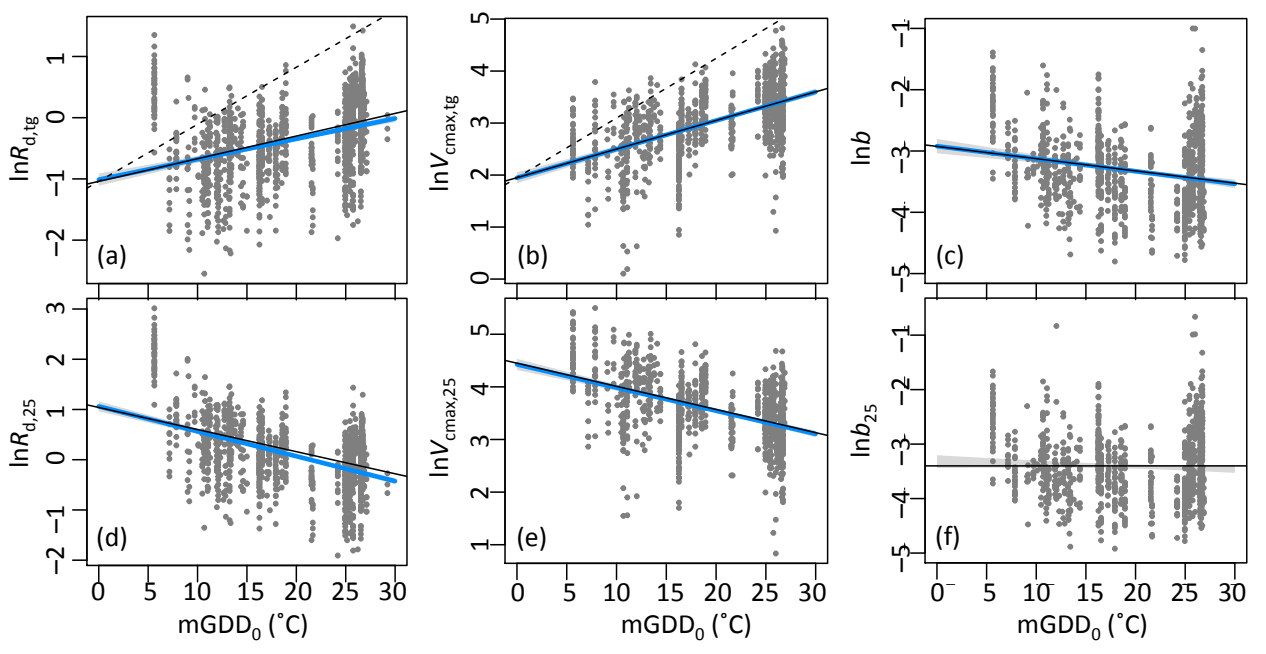